\title{
Applicability of contemporary quality indicators in vestibular surgery-do they accurately measure tumor inherent postoperative complications of vestibular schwannomas?
}

\author{
Stephanie Schipmann ${ }^{1}$ (1) - Sebastian Lohmann ${ }^{1} \cdot$ Bilal Al Barim ${ }^{1} \cdot$ Eric Suero Molina ${ }^{1} \cdot$ Michael Schwake $^{1}$. \\ Özer Altan Toksöz ${ }^{1}$. Walter Stummer ${ }^{1}$
}

Received: 1 February 2021 / Accepted: 28 October 2021 / Published online: 2 December 2021

(c) The Author(s) 2021

\begin{abstract}
Background Due to rising costs in health care delivery, reimbursement decisions have progressively been based on quality measures. Such quality indicators have been developed for neurosurgical procedures, collectively. We aimed to evaluate their applicability in patients that underwent surgery for vestibular schwannoma and to identify potential new disease-specific quality indicators.

Methods One hundred and three patients operated due to vestibular schwannoma were subject to analysis. The primary outcomes of interest were 30-day and 90-day reoperation, readmission, mortality, nosocomial infection and surgical site infection (SSI) rates, postoperative cerebral spinal fluid (CSF) leak, facial, and hearing function. The secondary aim was the identification of prognostic factors for the mentioned primary outcomes.

Results Thirty-day (90-days) outcomes in terms of reoperation were 10.7\% (14.6\%), readmission 9.7\% (13.6\%), mortality $1 \%(1 \%)$, nosocomial infection $5.8 \%$, and SSI $1 \%(1 \%)$. A 30 - versus 90 -day outcome in terms of CSF leak were $6.8 \%$ vs. $10.7 \%$, new facial nerve palsy $16.5 \%$ vs. $6.1 \%$. Hearing impairment from serviceable to non-serviceable hearing was $6.8 \%$ at both 30- and 90-day outcome. The degree of tumor extension has a significant impact on reoperation $(p<0.001)$, infection ( $p=0.015)$, postoperative hemorrhage $(p<0.001)$, and postoperative hearing loss $(p=0.026)$.

Conclusions Our data demonstrate the importance of entity-specific quality measurements being applied even after 30 days. We identified the occurrence of a CSF leak within 90 days postoperatively, new persistent facial nerve palsy still present 90 days postoperatively, and persisting postoperative hearing impairment to non-serviceable hearing as potential new quality measurement variables for patients undergoing surgery for vestibular schwannoma.
\end{abstract}

Keywords Vestibular schwannoma $\cdot$ Quality indicator $\cdot$ Facial nerve palsy $\cdot$ Readmission $\cdot$ Reoperation $\cdot$ Surgical site infection · Acoustic neurinoma

$\begin{array}{ll}\text { Abbreviations } \\ \text { OR } & \text { Odds ratio } \\ \text { CI } & \text { Confidence interval } \\ \text { CSF } & \text { Cerebrospinal fluid } \\ \text { VS } & \text { Vestibular schwannoma }\end{array}$

Stephanie Schipmann and Sebastian Lohmann contributed equally to this work.

This part of the Topical Collection on Brain Tumors

Stephanie Schipmann

stephanie.schipmann@ukmuenster.de

1 Department of Neurosurgery, University Hospital Münster, Albert-Schweitzer-Campus 1, 48149 Münster, Germany
STR Subtotal resection

CR Complete resection

SSEP Somatosensory evoked potential

EMG Electromyography

MEP Motor evoked potential

DNS Direct nerve stimulation

AEP Acoustic evoked potential

GS Gardner Robertson scale

\section{Introduction}

Vestibular schwannomas (VS) are slow growing, primarily benign brain tumors that arise from Schwann cells covering the vestibular portion of the 8 th cranial nerve $[6,17]$. 
Continuous advances in surgical procedures have led to considerably improved postoperative mortality and morbidity rates [48]. However, complete tumor resection while preserving facial and hearing functions remains highly challenging [31].

Efforts of mitigating complications in VS surgery have further gained attention considering the increasing relevance of standardized quality measures. Aiming at realizing the highest quality of delivered care at acceptable costs, risk stratification based on standardized quality indicators has become a central issue in many medical fields, including neurosurgery [30, 47]. In light of rising costs of health care delivery and changes in the policy of health care providers, reimbursement decisions have progressively been based on quality measures $[26,27]$.

While prognostic factors of VS on facial nerve preservation have extensively been discussed, analyses of further quality-related outcome measures are sparse $[4,15,16,22$, 56]. Presently used quality indicators have often been developed for all neurosurgical procedures and focus mainly on the first 30 postoperative days [45]. Hence, we aimed to analyze their applicability to the disease-inherent characteristics of VS and to evaluate the necessity of longer observation periods. The secondary aim of the study was the identification of associated risk factors of primary outcome measures. Understanding variables that increase the likelihood of adverse events as potential quality indicators will help defining more tumor-specific standards in vestibular surgery.

\section{Methods}

\section{Patient data}

All patients that underwent microsurgical VS resection between January 2013 and May 2019 at the Department of Neurosurgery, University Hospital Münster were retrospectively included in this study. Patients with Hannover T4 tumors operated in 2013 and 2014 were also subject to previous analysis [31]. Patients with neurofibromatosis type II and bilateral VS were excluded from the analysis due to a different treatment approach.

Baseline characteristics such as age, sex, presenting symptoms, surgical details, and patient's comorbidities were obtained from the electronic medical records of each patient.

Hearing function was stratified into normal hearing (Gardner Robertson scale (GS) grade 1), serviceable hearing (GS grade 2), and non-serviceable hearing (GS $\geq 3$ ) [19].

Facial nerve function was graded according to the House $\&$ Brackman classification [25]. Tumor growth was stratified according to the Hannover tumor extension grading scale [41] and size was measured using the largest tumor diameter including the intracanalicular portion.
The extent of resection (EOR) was categorized in complete resection (CR) (postoperative MR without contrast enhancement), near total resection (NTR) (any form of linear enhancement), and subtotal resection (STR) (measurable residue enhancement).

Secondary diagnoses were classified using the 19 items from the Charlson comorbidity index (CCI) and the ageadjusted CCI (ACCI) was calculated $[9,10]$. Only comorbidities present on admission were considered part of the patient's preadmission diagnosis profile.

\section{Outcomes of interest}

All adverse events were merged into the different categories of currently established quality metrics $[12,13,34,43$, $45-47,50]$. The primary outcomes of interest were 30-day and 90-days reoperation, readmission, mortality, nosocomial infection and surgical site infection (SSI) rates, postoperative cerebral spinal fluid (CSF) leak, hearing, and facial function. Data regarding EOR and recurrence were obtained.

Only unplanned reoperations and readmission were considered. Readmissions within 30/90 days to other hospitals were not recorded. Reasons for readmission were classified into CSF leak, SSI, new facial palsy, and unrelated, e.g., medical reasons. Reasons for reoperation comprised postoperative hemorrhage, SSI, CSF leak, and hydrocephalus.

New persistent facial nerve dysfunction was defined as HB grade III or higher function persisting for more than 3 months postoperatively. The secondary aim of the study was the identification of risk factor for the mentioned outcome measures. The study was approved by the local ethics committee (2018-128-f-S).

\section{Surgery and intraoperative neuromonitoring, routine follow-up}

Prior to surgery, the various treatment options comprising "wait and see," radiotherapy, or surgical resection were discussed with the patient, depending on tumor size, patient's wish, and comorbidities.

In case of small tumors (approx. $<2 \mathrm{~cm}$ diameter), all patients were seen by both a neurosurgeon and a radiooncologist to discuss surgical and radiation options.

A retrosigmoid approach was followed in all cases and resection was carried out as described before [31]. Routine monitoring of cranial nerves $\mathrm{V}$ (electromyography-EMG), VII (EMG, motor evoked potential-MEP, direct nerve stimulation-DNS), and VIII (acoustic evoked potential-AEP), as well as somatosensory evoked potentials (SSEP), were applied using ISIS Xpert (Inomed, Emmendingen, Germany). Direct stimulation of the tumor surface, monitored by facial EMG, was used to identify the position of the facial nerve prior to tumor resection. In addition, transcortical 
stimulation for monitoring of the facial nerve motor function was applied. Depending on the tumor size and extension additional cranial nerves were monitored. CR was performed whenever possible. The main aim of surgery was to preserve facial nerve function while resecting as much tumor as securely possible. Patients with STR only were either followed up with serial imaging or scheduled for radiation treatment after surgery. Decision making was based on the individual case.

Patients were routinely seen 6 weeks postoperatively for clinical evaluation and after 3 months for MRI follow-up in our outpatient department. In case of CR, MRI followup was performed yearly, and in patients with a residual tumor semiannual. In case of tumor recurrence, the various options (wait-and-see, radiosurgery and surgery) are discussed with the patients in consideration of tumor size, extension, patients wish, hearing, and facial nerve function.

\section{Statistical analyses}

Statistical analyses were performed using IBM SPSS Statistics 26.0 software (IBM, Armonk, New York, USA). We used absolute and relative frequencies for categorical variables and median and interquartile range for continuous variables. Chi-square test was used for categorical variables and $t$-test and Mann-Whitney $U$ test for continuous variables, as appropriate. All variables significant in the bivariate analyses were entered into a multivariable logistic regression model. Odds ratios (ORs) were calculated and obtained with corresponding 95\% confidence intervals (CIs). Time to event analysis was conducted using log-rank test. A twosided probability value $p$ of less than 0.05 was considered statistically significant.

\section{Results}

\section{Demographic data}

A total of 103 patients were included in this study, of whom $57.3 \%$ were female and $42.7 \%$ were male. A large majority of cases presented with newly diagnosed tumors $(n=90$, $87.4 \%)$.

Tumor location was distributed almost equally between the left $(n=52,50.5 \%)$ and right $(n=51,49.5 \%)$ site with a median tumor diameter of $2.1 \mathrm{~cm}$ (IQR 1.2). The majority of patients presented with a Hannover tumor extension grading scale T4a tumor $(n=46,44.7 \%)$.

The median follow-up time was 20 (IQR 35.75) months. Demographics and baseline characteristics of the study population are depicted in Table 1.

\section{Outcome variables}

Outcome rates and the time of onset after surgery are summarized in Table 2.

\section{Reoperation}

Patients were reoperated within 30 days in $10.7 \%(n=11)$ of cases. The main reason for early reoperation was a postoperative hemorrhage, which occurred in 6 cases (5.8\%) after a median of 2.5 days (IQR 3). Time to event analysis revealed that reoperation due to hydrocephalus and hemorrhage occurred within the first days after surgery and significantly earlier than reoperations due to CSF leak or SSI $(p=0.036)$. Most reoperations occurred during index admission (72.7\%, $n=8)$.

In comparison, the 90-day reoperation rate was $14.6 \%$; the difference between the 30-day period was based only on more patients with CSF leak.

\section{Readmission}

The 30-day readmission rate was $9.7 \%(n=10)$. Most readmissions were based on a CSF leak $(n=5,4.9 \%)$. In three cases $(2.9 \%)$, a secondary onset of a facial nerve dysfunction let to readmission. These patients were treated with intravenous acyclovir and steroids and in all cases, the facial nerve function normalized after a few weeks. There was no significant difference regarding the timing of readmission and the reason $(p=0.075)$. The 90 -day readmission rate was $13.6 \%$. Four more patients were readmitted between days 31 and 90 , the reason for readmission was mainly unrelated $(75 \%)$ and in one case due to CSF leak (25\%).

\section{Mortality rate}

The 30 - and 90 -day mortality rates were $1 \%$. The patient died due to pulmonary embolism.

\section{Nosocomial infection and surgical site infection}

A nosocomial infection was observed in $5.8 \%$ of cases $(n=6)$. Three patients $(2.9 \%)$ developed meningitis after a median of 7 days. The SSI rate in our collective was $1 \%$ $(n=1)$. No further infections manifested between days 31 and 90 , consequently, there was no difference between the 30-day and 90-day nosocomial and surgical site infections rates.

\section{Postoperative CSF leak}

The 30-day vs. 90-day postoperative CSF leak rate was $6.8 \%(n=7)$ vs. $10.7 \%(n=11)$. Nine patients $(8.7 \%)$ 
Table 1 Baseline characteristics of the 103 included cases

\begin{tabular}{|c|c|c|c|}
\hline & & $n$ & $\%$ \\
\hline Age & Median $(I Q R)$ & $53(18)$ & - \\
\hline \multirow[t]{2}{*}{ Sex } & Male & 44 & 42.7 \\
\hline & Female & 59 & 57.3 \\
\hline \multirow[t]{2}{*}{ Urgency of admission } & Elective & 101 & 98.1 \\
\hline & Emergency & 2 & 1.9 \\
\hline Primary diagnosis & & 90 & 87.4 \\
\hline \multirow[t]{3}{*}{ Recurrent tumor } & & 13 & 12.6 \\
\hline & Previous tumor resection & 7 & 6.8 \\
\hline & Previous tumor resection & 7 & 6.8 \\
\hline Focal neurological deficit preop & & 40 & 38.8 \\
\hline \multirow[t]{4}{*}{ Facial nerve function preop } & HB I & 94 & 91.3 \\
\hline & HB II & 7 & 6.8 \\
\hline & HB III & 1 & 1.0 \\
\hline & HB IV & 1 & 1.0 \\
\hline \multirow[t]{3}{*}{ Hearing function preop } & Normal & 21 & 20.4 \\
\hline & Serviceable & 71 & 68.9 \\
\hline & Non-serviceable & 11 & 10.7 \\
\hline \multirow[t]{2}{*}{ Tumor site } & Left & 52 & 50.5 \\
\hline & Right & 51 & 49.5 \\
\hline Tumor size $(\mathrm{cm})$ & Median, $I Q R$ & $2.1(1.2)$ & - \\
\hline \multirow[t]{6}{*}{ Hannover tumor extension grading scale } & $\mathrm{T} 1$ & 2 & 1.9 \\
\hline & $\mathrm{T} 2$ & 14 & 13.6 \\
\hline & $\mathrm{T} 3 \mathrm{a}$ & 13 & 12.6 \\
\hline & $\mathrm{T} 3 \mathrm{~b}$ & 17 & 16.5 \\
\hline & $\mathrm{T} 4 \mathrm{a}$ & 46 & 44.7 \\
\hline & $\mathrm{T} 4 \mathrm{~b}$ & 11 & 10.7 \\
\hline Hydrocephalus prior to surgery & & 9 & 8.7 \\
\hline \multirow[t]{3}{*}{ ECOG preop } & 0 & 91 & 88.3 \\
\hline & 1 & 10 & 9.7 \\
\hline & 2 & 2 & 1.9 \\
\hline \multirow[t]{3}{*}{ ASA preop } & 1 & 22 & 24.4 \\
\hline & 2 & 57 & 63.3 \\
\hline & 3 & 11 & 12.2 \\
\hline ACCI admission & Median $(I Q R)$ & $1(3)$ & - \\
\hline Number of secondary diagnoses & Median $(I Q R)$ & $0(0)$ & - \\
\hline Depression & & 11 & 10.7 \\
\hline Nicotine abuse & & 11 & 10.7 \\
\hline Leukocytosis ( $>10.900$ per $\mu \mathrm{l})$ preop & & 13 & 12.6 \\
\hline CRP (>1 mg/dl) preop & & 5 & 4.9 \\
\hline Length of surgery (min) & Median $(I Q R)$ & $350(128)$ & 128 \\
\hline \multirow[t]{3}{*}{ Extent of resection } & $\mathrm{CR}$ & 43 & 41.7 \\
\hline & NTR & 20 & 19.6 \\
\hline & STR & 39 & 38.2 \\
\hline Length of stay & Median $(I Q R)$ & $8(3)$ & - \\
\hline Length of stay on ICU & Median $(I Q R)$ & $1(0)$ & - \\
\hline
\end{tabular}

$I Q R$, interquartile range; preop, preoperative; $E C O G$, Eastern Cooperative Oncology Group; ASA, American Society of Anesthesiologists; $A C C I$, age-adjusted Charlson comorbidity index; $C R P$, C-reactive protein; $C R$, complete resection; $S T R$, subtotal resection; $I C U$, intensive care unit 
Table 2 Incidence of postoperative adverse events

\begin{tabular}{|c|c|c|c|}
\hline \multirow[t]{2}{*}{ Outcome } & \multirow{2}{*}{$\begin{array}{l}\text { Cumu- } \\
\text { lative } \\
\text { incidence } \\
n(\%)\end{array}$} & \multicolumn{2}{|c|}{$\begin{array}{l}\text { Time to event } \\
\text { (days) }\end{array}$} \\
\hline & & Median & IQR \\
\hline 30-day reoperation & $11(10.7)$ & 3.0 & 13 \\
\hline Postoperative hemorrhage & $6(5.8)$ & 2.5 & 3 \\
\hline CSF leak & $2(1.9)$ & 17 & - \\
\hline Surgical site infection & $1(1.0)$ & 18 & - \\
\hline Hydrocephalus & $2(1.9)$ & 1.5 & - \\
\hline 90-day reoperation & $15(14.6)$ & 4.0 & 32 \\
\hline Postoperative hemorrhage & $6(5.8)$ & 2.5 & 3 \\
\hline CSF leak & $6(5.8)$ & 44 & 40 \\
\hline Surgical site infection & $1(1.0)$ & 18 & - \\
\hline Hydrocephalus & $2(1.9)$ & 1.5 & - \\
\hline 30-day readmission & $10(9.7)$ & 7 & 18 \\
\hline CSF leak & $5(4.9)$ & 13.5 & 18 \\
\hline Surgical site infection & $1(1.0)$ & 10 & - \\
\hline New facial nerve palsy & $3(2.9)$ & 3 & - \\
\hline Unrelated* $^{*}$ & $1(1.0)$ & 23 & - \\
\hline 90-day readmission & $14(13.6)$ & 15 & 26 \\
\hline CSF leak & $6(5.8)$ & 15 & 26 \\
\hline Surgical site infection & $1(1.0)$ & 10 & - \\
\hline New facial nerve palsy & $3(2.9)$ & 3 & - \\
\hline Unrelated $^{*}$ & $4(3.9)$ & 44.5 & 51 \\
\hline 30-day mortality & $1(1.0)$ & 2 & - \\
\hline 90-day mortality & $1(1.0)$ & 2 & - \\
\hline 30- and 90-day nosocomial infection & $6(5.8)$ & 15.5 & 14 \\
\hline Meningitis & $3(2.9)$ & 7 & - \\
\hline Pneumonia & $1(1.0)$ & 14 & - \\
\hline Surgical site infection & $1(1.0)$ & 17 & - \\
\hline Sepsis & $1(1.0)$ & 30 & - \\
\hline 30-day surgical site infection & $1(1.0)$ & 17 & - \\
\hline 90-day surgical site infection & $1(1.0)$ & 17 & - \\
\hline 30-day CSF leak & $7(6.8)$ & 5 & 12 \\
\hline 90-day CSF leak & $11(10.7)$ & 14 & 38 \\
\hline 30-day facial nerve dysfunction** & $17(16.5)$ & N/A & - \\
\hline $\begin{array}{l}\text { 90-day persistent facial nerve dysfunc- } \\
\text { tion** }\end{array}$ & $6(6.1)$ & N/A & - \\
\hline 30-day non-serviceable hearing $* * *$ & $7(6.8)$ & N/A & - \\
\hline 90-day non-serviceable hearing $* * *$ & $7(6.8)$ & N/A & - \\
\hline
\end{tabular}

*Unrelated = worsening of general condition not related to surgery

** Defined as new facial nerve palsy $\geq$ HB grade III

${ }^{* * *}$ Worsening of hearing from Gardner-Robinson grade $1 / 2$ to grade $\geq 3$ (non-serviceable hearing)

$N / A$, not applicable; $C S F$, cerebrospinal fluid

required a lumbar drain and surgical revision was required in 6 cases (5.8\%). The median time to onset of a CSF leak was 14 days (IQR 38). The maximal time between surgery and CSF leak was 71 days.

\section{Persistent facial nerve dysfunction}

Most patients $(n=94,91.3 \%)$ presented with intact facial nerve function prior to surgery (Table 1).

Figure 1a shows the course of the facial nerve function regarding the different time points before and after surgery. One-quarter of patients $(n=26,25.2 \%)$ showed an initial worsening of facial function within the first 30 days after surgery. However, a persistent facial nerve dysfunction still present at 90 days postoperatively was observed in only 6 cases $(6.1 \%)$, indicating that facial nerve functions improves during the early postoperative course. In detail, 4 patients worsened from normal function (HB I) to HB III, and one patient each from HB I to HB V and HB II to HB III. Except for one patient, all patients that showed a new postoperative facial nerve dysfunction improved in long-term follow-up. In half of those cases $(50 \%, n=3)$, facial function was normalized in long-term follow-up.

Figure $1 \mathrm{~b}$ shows the outcome regarding facial nerve function 90 days postoperatively depending on the tumor extension according to the Hannover classification. There is a clear tendency that a higher Hannover grade leads to a higher probability of a persistent postoperative facial nerve dysfunction without reaching statistical significance $(p=0.980)$.

Out of the patients undergoing STR $8.9 \%$ were confronted with a new postoperative persistent facial nerve dysfunction still present 90 days postoperatively. In contrast, $2.3 \%$ of patients out of CR group have suffered facial nerve injuries $(p=0.172)$.

\section{Postoperative hearing}

The majority of patients presented with impaired hearing prior to surgery $(n=71,68.9 \%)$. Eleven patients had singlesided non-serviceable hearing $(10.7 \%)$. The hearing was worse in 16 cases (15.5\%) after surgery, 7 patients developed non-serviceable hearing $(6.8 \%)$, and mild hearing impairment was observed in 9 patients $(8.7 \%)$ (Fig. 2a). There was no difference between immediate, 30-day, and 90-day rates of new non-serviceable hearing. Figure $2 b$ shows the hearing outcome depending on the tumor extension. Our data revealed a tendency for T3a tumors to be associated with a higher risk for postoperative worsening of hearing without reaching statistical significance $(p=0.126)$.

\section{Tumor recurrence}

The overall recurrence rate was $8.7 \%$ (7/103). The median time to recurrence was 30 months (range: $18-50$ months).

The recurrence rate depended significantly on the EOR (recurrence rate for CR: 0\% (0/43), NTR: 10\% (2/20), STR: $17.9 \%(7 / 39), p=0.016)$. 
Fig. 1 a Course of the facial nerve function regarding the different time points (preoperative, postoperative (within 30 days) and short-term FU (90 days) and after $>3$ months (long-term FU). FU, follow-up. b Facial nerve function three months postoperative in relation to the tumor extension according to the Hannover classification. There is a clear tendency that a higher Hannover grade leads to a higher probability of a persistent postoperative facial nerve dysfunction without reaching statistical significance $(p=0.980)$. HB, House \& Brackman a

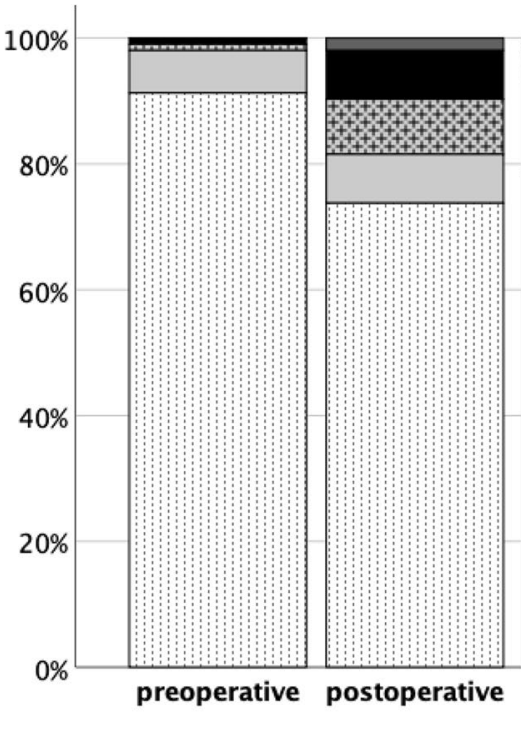

House-Brackmann scale

$\square$ HB V

HB IV FHB III

$\square B$
$\mathrm{HB}$ II b

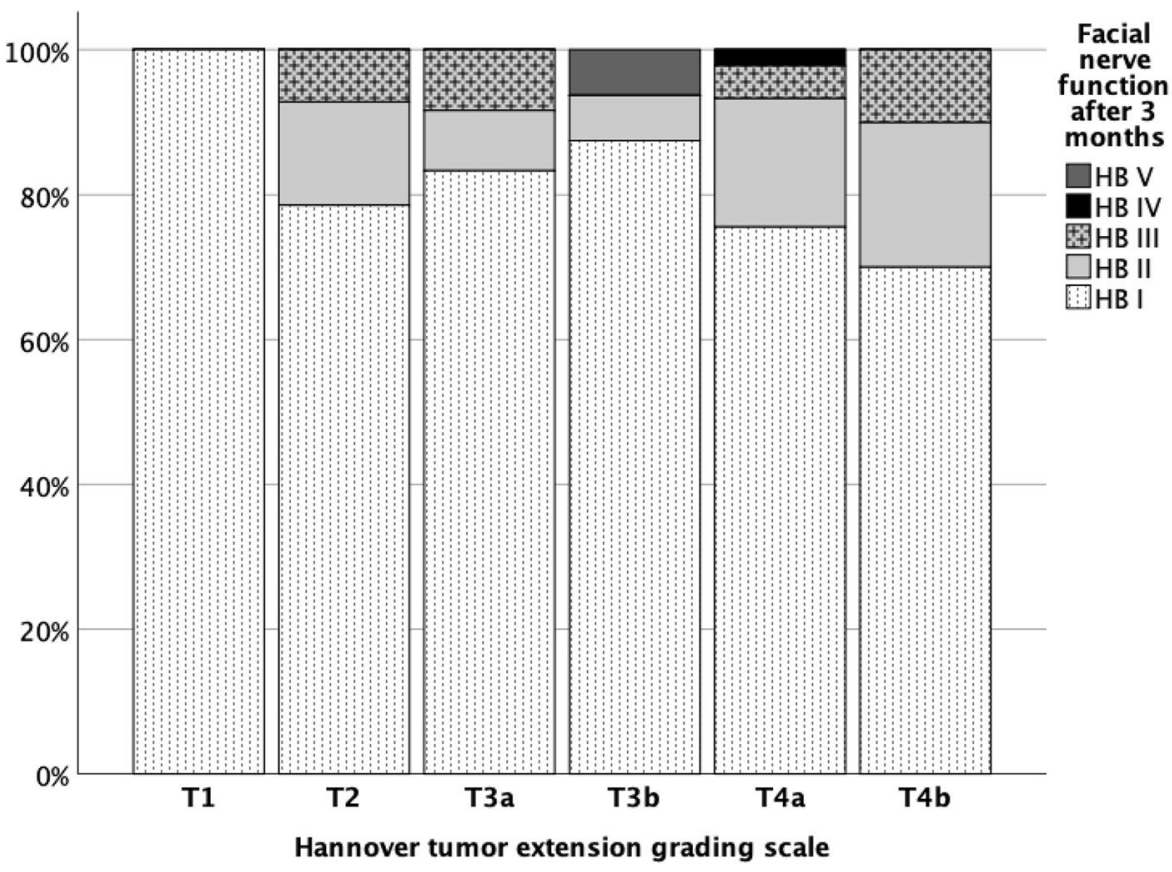

Most patients were treated with GammaKnife when diagnosed with tumor recurrence $(66.7 \%, 6 / 9)$. Three patients $(33.3 \%)$ were surgically treated with two of them being treated with additional postoperative GammaKnife.

\section{Extent of resection}

CR was performed in $41.7 \%(n=43)$, whereas NTR was documented in $19.6 \%(n=20)$ and STR in $38.2 \%(n=39)$ (Table 1). In one case, there was no postoperative MRI available for defining the EOR. Of patients with STR, 33.3\% received postoperative radiation therapy (GammaKnife: $n=10,76.9 \%$, conventional radiotherapy $n=2,15.4 \%$, and CyberKnife $n=1,7.7 \%$ ).

\section{Risk factors for primary outcome measures/adverse events}

Several variables have proved to have a significant impact on more than just one quality indicator in vestibular schwannoma surgery. Overall, the degree of tumor extension, graded according to the Hannover classification scheme, has showed to significantly impact 30-day reoperation $(p<0.001), 30$-day nosocomial infection $(p=0.015)$, postoperative hemorrhage $(p<0.001)$, and postoperative 
Fig. 2 a Pre- and postoperative hearing status. GS, Gardner Robertson scale. b Postoperative hearing status in relation to the tumor extension according to the Hannover classification. There was no significant difference between hearing status and tumor extension grade $(p=0.126)$ a

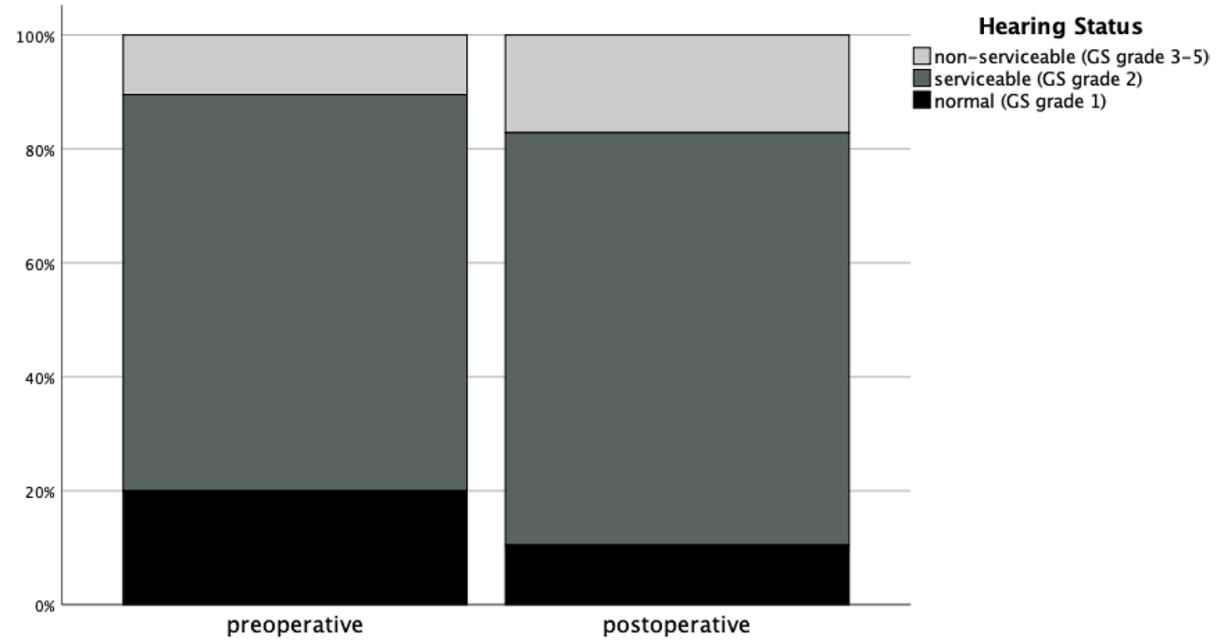

b

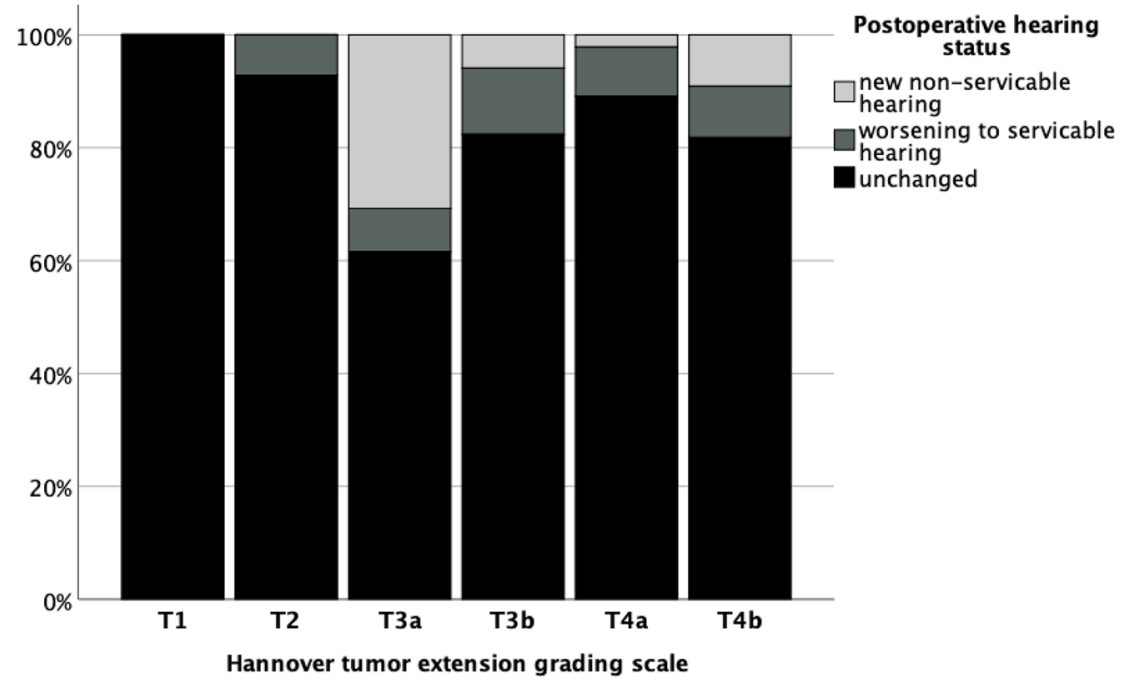

hearing loss $(p=0.026)$. In addition, hydrocephalus prior to surgery has shown to impinge upon different outcome values: 30 -day reoperation ( $p$-value $<0.001), 30$-day nosocomial infection $(p$-value $=0.028)$, and postoperative hemorrhage $(p$-value $<0.001)$. Similarly, postoperative hydrocephalus $(p$-value $<0.001)$ and postoperative hemorrhage ( $p$-value $<0.001$ ) raise the likelihood of nosocomial infections.

A 30-day readmission was mainly affected by alcohol abuse $(p=0.019)$, depression $(p<0.037)$, and nicotine abuse $(p<0.037)$. Male patients were confronted with a significantly higher probability of a CFS leak $(p=0.033)$, whereas elderly patients faced a higher risk of postoperative hemorrhage $(p=0.006)$. Results from the univariate analysis are summarized in Table 3.

Multivariate analysis revealed a male sex as a predictor of CFS leak $(\mathrm{OR}=4.15,95 \%$-CI $=1.03-16.68, p=0.045)$.

Moreover, age was found to be an independent risk factor of postoperative hemorrhage (OR, 1.12; CI, 1.02-1.24; $p=0.025$ ). Additional potential risk predictors retrieved from univariate logistic regression analyses did not prove sufficient significance in the multivariate setting.

\section{Discussion}

Despite advances in surgical techniques and perioperative management, short-term postoperative complications, and adverse events in VS surgery remain present.

Our study provides an overview of common postoperative complications and tumor inherent adverse events in VS surgery with regard to currently applied quality measures and provides data on the 30- and 90-day postoperative outcome. It has been widely discussed that health care providers apply different quality indicators to measure the quality of the delivered care and to justify reimbursement processes. Most of these quality indicators are closely connected to the occurrence of postoperative complications [44]. This justifies the analysis of predictors associated with adverse events, 
Table 3 Risk factors for the different outcome variables obtained in univariate analysis. All variables that are presented in Table 1 were subject to analysis. In this table only significant results $(p<0.05)$ are shown

\begin{tabular}{|c|c|c|c|c|}
\hline \multicolumn{5}{|l|}{ 30-day reoperation } \\
\hline & & Reoperation $n(\%)$ & No reoperation $n(\%)$ & $p$-value \\
\hline \multirow[t]{3}{*}{ Tumor size } & & Median, 2.90 (IQR, 2.1) & Median, 2.0 (IQR, 1.2) & 0.022 \\
\hline & $<2 \mathrm{~cm}$ & $6(7.1 \%)$ & $78(92.9 \%)$ & 0.015 \\
\hline & $\geq 2 \mathrm{~cm}$ & $5(26.3 \%)$ & $14(73.7 \%)$ & \\
\hline \multirow[t]{6}{*}{ Hannover classification } & 1 & $0(0.0 \%)$ & $2(100 \%)$ & $<0.001$ \\
\hline & 2 & $0(0.0 \%)$ & $14(100 \%)$ & \\
\hline & $\mathbf{3 a}$ & $1(7.7 \%)$ & $12(92.3 \%)$ & \\
\hline & $\mathbf{3 b}$ & $3(17.6 \%)$ & $14(82.4 \%)$ & \\
\hline & $\mathbf{4 a}$ & $1(2.2 \%)$ & $45(97.8 \%)$ & \\
\hline & $4 b$ & $6(54.5 \%)$ & $5(45.5 \%)$ & \\
\hline \multirow[t]{2}{*}{ Hydrocephalus preop surgery } & yes & $5(55.6 \%)$ & $4(44.4 \%)$ & $<0.001$ \\
\hline & no & $6(6.4 \%)$ & $88(93.6 \%)$ & \\
\hline \multicolumn{5}{|l|}{ 30-day nosocomial infection } \\
\hline & & Nosocomial infection $n(\%)$ & No nosocomial infection $n(\%)$ & $p$-value \\
\hline \multirow[t]{2}{*}{ Hydrocephalus preop surgery } & yes & $2(22.2 \%)$ & $7(77.8 \%)$ & 0.028 \\
\hline & no & $4(4.3 \%)$ & $90(95.7 \%$ & \\
\hline \multirow[t]{6}{*}{ Hannover classification } & 1 & $1(50 \%)$ & $1(50 \%)$ & 0.015 \\
\hline & 2 & $0(0 \%)$ & $14(100 \%)$ & \\
\hline & $3 \mathbf{a}$ & $0(0 \%)$ & $13(100 \%)$ & \\
\hline & $\mathbf{3 b}$ & $2(11.8 \%)$ & $15(88.2 \%)$ & \\
\hline & $4 a$ & $1(2.2 \%)$ & $45(97.8 \%)$ & \\
\hline & $4 b$ & $2(18.2 \%)$ & $9(81.8 \%)$ & \\
\hline \multirow[t]{2}{*}{ 30-day reoperation } & yes & $4(36.4 \%)$ & $7(63.6 \%)$ & $<0.001$ \\
\hline & no & $2(2.2 \%)$ & $90(97.8 \%)$ & \\
\hline \multirow[t]{2}{*}{ Hydrocephalus postoperative } & yes & $3(33.3 \%)$ & $6(66.7 \%)$ & $<0.001$ \\
\hline & no & $3(3.2 \%)$ & $91(96.8 \%)$ & \\
\hline \multirow[t]{2}{*}{ Postoperative hemorrhage } & yes & $3(42.9 \%)$ & $4(57.1 \%)$ & $<0.001$ \\
\hline & no & $3(3.1 \%)$ & $93(96.9 \%)$ & \\
\hline \multicolumn{5}{|l|}{ 30-day readmission } \\
\hline & & Readmission $n(\%)$ & Not readmission $n(\%)$ & $p$-value \\
\hline \multirow[t]{2}{*}{ Alcohol abuse } & yes & $2(40.0 \%)$ & $3(60.0 \%)$ & 0.019 \\
\hline & no & $8(8.2 \%)$ & $90(91.8 \%)$ & \\
\hline \multirow[t]{2}{*}{ Depression } & yes & $3(27.3 \%)$ & $8(72.7 \%)$ & 0.037 \\
\hline & no & $7(7.6 \%)$ & $85(92.4 \%)$ & \\
\hline \multirow[t]{2}{*}{ Nicotine abuse } & yes & $3(27.43 \%)$ & $8(72.7 \%)$ & 0.037 \\
\hline & no & $7(7.6 \%)$ & $85(92.4 \%)$ & \\
\hline \multicolumn{5}{|l|}{ CFS leakage } \\
\hline & & CFS leakage $n(\%)$ & No CFS leakage $n(\%)$ & $\mathrm{p}$-value \\
\hline \multirow[t]{2}{*}{ Sex } & Male & $8(18.2 \%)$ & $36(81.8 \%)$ & 0.033 \\
\hline & Female & $3(5.1 \%)$ & $56(94.9 \%)$ & \\
\hline \multicolumn{5}{|l|}{ Postoperative hemorrhage } \\
\hline & & Hemorrhage $n(\%)$ & No hemorrhage $n(\%)$ & $p$-value \\
\hline \multirow[t]{6}{*}{ Hannover classification } & 1 & $0(0 \%)$ & $2(100 \%)$ & $<0.001$ \\
\hline & 2 & $0(0 \%)$ & $14(100 \%)$ & \\
\hline & $\mathbf{3 a}$ & $0(0 \%)$ & $13(100 \%)$ & \\
\hline & $\mathbf{3 b}$ & $2(11.8 \%)$ & $15(88.2 \%)$ & \\
\hline & $4 \mathbf{a}$ & $0(0 \%)$ & $46(100 \%)$ & \\
\hline & $4 b$ & $5(45.5 \%)$ & $6(54.5 \%)$ & \\
\hline Hydrocephalus preop surgery & yes & $4(44.4 \%)$ & $5(55.6 \%)$ & $<0.001$ \\
\hline
\end{tabular}


Table 3 (continued)

\begin{tabular}{|c|c|c|c|c|}
\hline & no & $3(3.2 \%)$ & $91(96.8 \%)$ & \\
\hline Age & Median (IQR) & $70(30)$ & $52(17)$ & 0.006 \\
\hline \multicolumn{5}{|c|}{ Postoperative non-serviceable hearing } \\
\hline & & Non-serviceable hearing $n(\%)$ & No hearing loss $n(\%)$ & $p$-value \\
\hline \multirow[t]{6}{*}{ Hannover classification } & 1 & $0(0 \%)$ & $2(100 \%)$ & 0.026 \\
\hline & 2 & $0(0 \%)$ & $13(100 \%)$ & \\
\hline & 3a & $4(30.8 \%)$ & $9(69.2 \%)$ & \\
\hline & $3 \mathbf{b}$ & $1(7.1 \%)$ & $13(92.9 \%)$ & \\
\hline & $4 a$ & $1(2.5 \%)$ & $39(97.5 \%)$ & \\
\hline & $4 \mathbf{b}$ & $1(10 \%)$ & $9(90 \%)$ & \\
\hline \multirow[t]{2}{*}{ Previous radiotherapy } & yes & $2(50 \%)$ & $2(50 \%)$ & 0.001 \\
\hline & no & $5(5.7 \%)$ & $83(94.3 \%)$ & \\
\hline
\end{tabular}

$I Q R$, interquartile range

also allowing the development of strategies for risk adjustment between different health care providers.

Several quality indicators have been suggested for the field of neurosurgery, among them 30-day readmission, mortality, reoperation, nosocomial, and SSI rate [12, 13, 34, 43, 45-47, 50]. However, we are convinced that a more disease-specific approach when using quality indicators will be advantageous, especially in VS surgery. In the following, we discuss the various existing quality indicators, their time frame, and introduce new, more disease-specific outcome measures.

\section{Classical quality indicators}

Commonly used quality indicators for several surgical fields are the 30-day reoperation and readmission rate. The usefulness and limitations of these indicators and the need for adequate risk adjustment have been widely discussed [12-14, 45, 46, 50].

Reported 30-day reoperation rates and readmission rates at the respective center corroborate the existing literature: Patients were readmitted to the hospital within 30 days in $9.7 \%$ and underwent a second surgery in $10.7 \%$ compared to documented incidence rates of 11.0-17.27\% for unplanned readmissions and 5.93-8.0\% for unplanned reoperations, respectively $[3,22,35,37]$.

For a better understanding of these factors, the analysis of the reasons for readmissions and reoperations is mandatory. We found that most reoperations were performed due to postoperative hemorrhage $(n=6,54.5 \%)$, followed by CSF leak $(n=2,18.2 \%)$. These data are in accordance with other studies [3]. The main reasons for readmission were CSF leak $(n=5,50 \%)$ and the onset of a delayed new delayed facial palsy $(n=3,30 \%)$.

Factors associated with a higher risk for 30-day reoperation were tumor size, higher grade in Hannover classification, and presence of a preoperative hydrocephalus; neither of them can be modified by the surgeon. On the contrary, univariate analysis revealed alcohol and nicotine abuse as well as depression being associated with readmission.

Thanks to an evolution in microsurgical techniques, 30-day mortality rates could have been drastically reduced from more than $10 \%$ to less than $1 \%$ over the past decades, which coincide with our cohort [3, 24, 33, 52]. The fortunately low incidence rate of perioperative mortality does not qualify this rate as an appropriate quality indicator for VS surgery due to lack of risk associated factors, impeding risk adjustment.

We found the nosocomial infection rate $(5.8 \%)$ to be in line with established literature values ranging from 0.24 to $10 \%[3,24]$. Risk factors for nosocomial infection in our collective were pre- and postoperative hydrocephalus, higher Hannover tumor classification, early reoperation, and postoperative hemorrhage. All these factors are linked to prolonged length of hospital stay and intensive care unit (ICU) stay, predisposing for the development of nosocomial infections [43, 48], and again underlining the importance of adequate risk adjustment when using this variable as a quality indicator.

\section{CSF leak}

CSF leak was implicated in half of all readmissions and $18.2 \%$ of all reoperations within 30 days and $40 \%$ of all reoperations within 90 days. Overall, an incidence of $10.7 \%$ within 90 days is in accordance with recent findings ranging from 6.0 to $14.1 \%[1,2,11]$. With respect to the high impact of CSF leak on the aforementioned quality measures, integrating means to minimize the risk for CSF leak into clinical practice is highly advisable. While recent studies found obesity to be a prognostic factor of CSF leaks [21], our analysis could not confirm this relationship and revealed 
male sex (OR, 4.15) in accordance with a large series of 6820 patients to be at greater risk for CSF leaks [1].

\section{New onset of facial nerve palsy}

A major challenge in VS surgery is the preservation of the facial nerve function as it inherently entails-despite constant enhancement in microsurgical techniques and monitoring modalities-a considerable risk of intraoperative damage of the facial nerve [40, 42].

Overall, $6.1 \%$ of all patients in our cohort developed a persistent facial nerve dysfunction ( $\geq$ HB III) still persistent at 90 days postoperatively - a relatively low value compared to reported incidence rates of facial palsy ranging from 4.8 to $41 \%[8,16]$.

Based on the premise that both preservation of facial nerve and total resection of large tumors may be highly challenging, the concept of functional sparing surgery, condoning a near-complete tumor resection is preferred by the majority of VS surgeons, including our neurosurgical department $[8,31,39]$. Together with adequate intraoperative facial nerve monitoring, the rate of postoperative facial nerve palsy could be lowered considerably during the last decade $[23,54]$.

The rate of postoperative persistent facial nerve dysfunction ( $\geq$ HB III) can be seen as a useful quality indicator when assessing outcome in VS surgery. Obviously, this indicator has to be evaluated in relation to the EOR, aiming at maximal safe resection, while preserving the facial nerve integrity. Possible variables for preoperative risk adjustment and benchmarking purposes are tumor size $[4,20]$, history of previous VS surgery [18,54], cystic tumor morphology [53], all factors that have been shown to be associated with a higher risk for nerve damage. A further risk factor is the degree of adhesiveness [4, 53]; however, this variable is not appropriate for risk adjustment as it cannot be clearly evaluated preoperatively.

In accordance with other studies [3, 4, 23, 36, 54], our data show that the EOR is not a predictive risk factor of postoperative facial nerve palsy, providing again evidence for maximal safe and facial function sparing resection.

\section{Postoperative non-serviceable hearing}

An important factor that has a huge impact on the patient's quality of life is postoperative hearing function [55]. Postoperative manifestation of single-sided non-serviceable hearing can be likewise seen as an indicator for quality. Tumor size and previous radiotherapy were identified as risk factors for hearing loss in our collective. In addition, impaired preoperative hearing has been found as a risk factor [5, 57]. These variables should be considered for preoperative risk adjustment. The rate of postoperative non-serviceable hearing was $6.8 \%$ in our cohort, compared to reported rates of $8.0 \%-47.0 \%[28,32]$.

\section{Timing of measuring of quality}

Most classical quality indicators refer to adverse events within a time period of 30 days after surgery (e.g., 30-day reoperation, readmission, mortality, and infection). We analyzed in addition the matching 90-day rates and could not show that the prolonged observation period detects other complications than CSF leak. In the respective cohort, $36.4 \%$ of all documented CSF leaks occurred more than 30 days after surgery. We therefore suggest to add "CSF leak" as a quality indicator covering the first 90 postoperative days, while keeping readmission, reoperation, mortality, and infection rates in the classical 30-day period.

In contrast, the rate of facial nerve dysfunction should not be evaluated before 3 months as an initial postoperative worsening of the facial function is likely to occur and recover, as both our data (30-day facial nerve dysfunction rate of $16.5 \%$ vs. 90 -day rate of $6.1 \%$ ) and many other studies could show $[8,54]$. We did not document improving of hearing function during the 30 - and 90 -day postoperastive course, so that this outcome can be used as an immediate postoperative quality indicator.

Tumor control and recurrence rate are subject to long time outcome and should be evaluated after months/years. We summarized the recommended time frames for all discussed quality indicators in Fig. 3.
Fig. 3 Recommendation for postoperative follow-up and recommended time for obtaining the various quality indicators

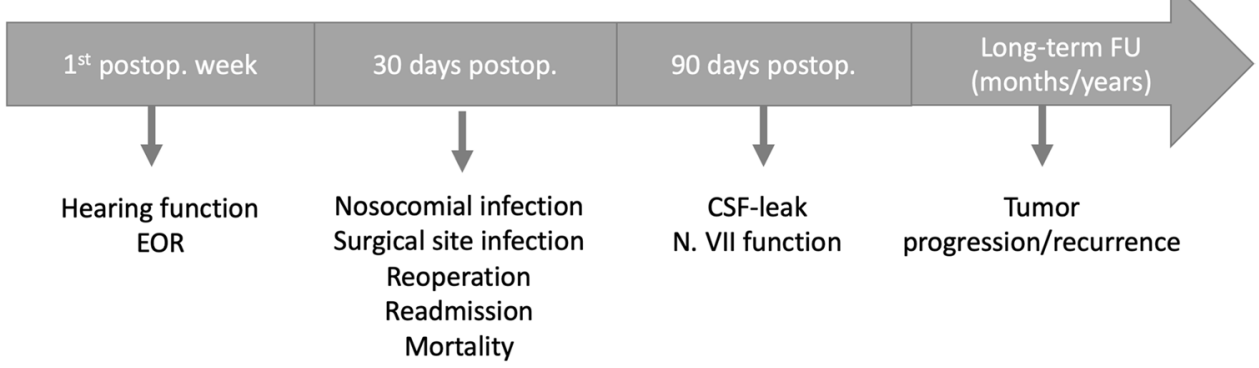




\section{General aspects for assessment of quality and application of quality indicators in VS surgery}

A common limitation of the suggested and already in some extent used quality indicators is their neglect of the longterm outcome, especially regarding tumor control. Extent of tumor resection has a strong influence on tumor recurrence $[38,49]$. Therefore, outcome in VS surgery should always be evaluated on the background of maximal safe resection. If safe resection is not possible, combination of intended submaximal resection followed by radiosurgery showed promising results [51].

Tumor size appears to be a predominant factor when anticipating adverse events and outcome measures and therefore has to be considered as the main variable for risk adjustment when applying quality indicators.

A further quality indicator that could be suitable for vestibular schwannoma surgery-but that was not in the scope of our study - is quality of life (QoL) of patients. Surprisingly, the impact of hearing loss, facial nerve function and tinnitus on QoL is less by comparison to ongoing dizziness and headache [7].

\section{Limitations}

The study is limited by the fact that data have been derived from a single hospital. However, all surgeries were carried out by the same surgeon. Despite these constant conditions assuring highly reliable results, their generalizability deserves additional discussion.

The data collection period extended from January 2013 and May 2019. During long observation periods, clinical procedures may have changed, and new surgical technologies could have been developed. However, all relevant international and national guidelines for the treatment of VS have not substantially changed. VS occurring with and incidence of 11 per million people, a comparatively long observation interval was inevitable for providing a robust volume of 103 cases [29].

Furthermore, the actual readmission rate could be higher than documented. Patients may have been readmitted to a different hospital and thus not accurately recorded in this study.

Multivariate analyses of the outcome variables "30-day reoperation" and "30-day readmission" have proved to be difficult. A larger sample size would have led to higher statistical power. However, univariate analyses remain valuable for identifying clinically relevant prognostic factors for all outcome variables.

As the study is designed in a retrospective setting, it is prone to the biases associated with this research method. It is well known that there are several surgical approaches for VS surgery, each bearing different risks for the presented outcome and quality measures. Our data applies only to tumor resection via the retrosigmoid approach.

\section{Conclusions}

We presented an overview of tumor inherent postoperative complications in VS surgery in relation to currently available quality indicators for the field of neurosurgery. Measuring the quality of care for certain diseases, the application of specific quality indicators appears to be useful. Our analysis has revealed three outcomes that appear useful as quality indicators in VS surgery: the occurrence of a CSF leak within 90 days, new and still persistent facial nerve palsy 90 days postoperatively, and postoperative hearing impairment to non-serviceable hearing. All outcomes are relatively common and easy to monitor. In contrast to already established classical quality indicators, which refer to the first 30 postoperative days only, longer observation periods (90 days) are warranted when applying CSF leak and onset of a new persistent facials nerve palsy as quality measures. Prospective multicenter studies are needed to evaluate the utility of the proposed indicators and to design adequate methods for risk adjustment.

Funding Open Access funding enabled and organized by Projekt DEAL.

\section{Declarations}

Ethical approval All procedures performed in studies involving human participants were in accordance with the ethical standards of the institutional and/or national research committee and with the 1964 Helsinki declaration and its later amendments or comparable ethical standards.

Informed consent Informed consent was obtained from all individual participants included in the study.

Conflict of interest Professor Stummer reports consultant and lecture activities for medac (Wedel, Germany), Carl Zeiss Meditech (Oberkochen, Germany), and NxDc (Lexington, Kentucky). Dr. Stephanie Schipmann and Dr. Michael Schwake report consultant activities for MagForce (Berlin, Germany). All other authors certify that they have no affiliations with or involvement in any organization or entity with any financial interest (such as honoraria; educational grants; participation in speakers' bureaus; membership, employment, consultancies, stock ownership, or other equity interest; and expert testimony or patent-licensing arrangements), or non-financial interest (such as personal or professional relationships, affiliations, knowledge or beliefs) in the subject matter or materials discussed in this manuscript.

Open Access This article is licensed under a Creative Commons Attribution 4.0 International License, which permits use, sharing, adaptation, distribution and reproduction in any medium or format, as long as you give appropriate credit to the original author(s) and the source, provide a link to the Creative Commons licence, and indicate if changes were made. The images or other third party material in this article are 
included in the article's Creative Commons licence, unless indicated otherwise in a credit line to the material. If material is not included in the article's Creative Commons licence and your intended use is not permitted by statutory regulation or exceeds the permitted use, you will need to obtain permission directly from the copyright holder. To view a copy of this licence, visit http://creativecommons.org/licenses/by/4.0/.

\section{References}

1. Alattar AA, Hirshman BR, McCutcheon BA, Chen CC, Alexander T, Harris J, Carter BS (2018) Risk Factors for readmission with cerebrospinal fluid leakage within 30 days of vestibular schwannoma surgery. Neurosurgery 82:630-637. https://doi.org/10.1093/ neuros/nyx 197

2. Bani A, Gilsbach JM (2002) Incidence of cerebrospinal fluid leak after microsurgical removal of vestibular schwannomas. Acta Neurochir (Wien) 144:979-982; discussion 982. https://doi.org/ 10.1007/s00701-002-0981-y

3. Bartek J Jr, Forander P, Thurin E, Wangerid T, Henriksson R, Hesselager G, Jakola AS (2019) Short-Term surgical outcome for vestibular schwannoma in Sweden: a nation-wide registry study. Front Neurol 10:43. https://doi.org/10.3389/fneur.2019.00043

4. Bloch O, Sughrue ME, Kaur R, Kane AJ, Rutkowski MJ, Kaur G, Yang I, Pitts LH, Parsa AT (2011) Factors associated with preservation of facial nerve function after surgical resection of vestibular schwannoma. J Neurooncol 102:281-286. https://doi. org/10.1007/s11060-010-0315-5

5. Brackmann DE, Owens RM, Friedman RA, Hitselberger WE, De la Cruz A, House JW, Nelson RA, Luxford WM, Slattery WH 3rd, Fayad JN (2000) Prognostic factors for hearing preservation in vestibular schwannoma surgery. Am J Otol 21:417-424. https:// doi.org/10.1016/s0196-0709(00)80054-x

6. Brodhun M, Stahn V, Harder A (2017) Pathogenesis and molecular pathology of vestibular schwannoma. HNO 65:362-372. https://doi.org/10.1007/s00106-016-0201-3

7. Carlson ML, Tveiten OV, Driscoll CL, Goplen FK, Neff BA, Pollock BE, Tombers NM, Lund-Johansen M, Link MJ (2015) What drives quality of life in patients with sporadic vestibular schwannoma? Laryngoscope 125:1697-1702. https://doi.org/10.1002/ lary. 25110

8. Carlstrom LP, Copeland WR 3rd, Neff BA, Castner ML, Driscoll CL, Link MJ (2016) Incidence and risk factors of delayed facial palsy after vestibular schwannoma resection. Neurosurgery 78:251-255. https://doi.org/10.1227/NEU.0000000000001015

9. Charlson M, Szatrowski TP, Peterson J, Gold J (1994) Validation of a combined comorbidity index. J Clin Epidemiol 47:1245-1251

10. Charlson ME, Pompei P, Ales KL, MacKenzie CR (1987) A new method of classifying prognostic comorbidity in longitudinal studies: development and validation. J Chronic Dis 40:373-383

11. Copeland WR, Mallory GW, Neff BA, Driscoll CL, Link MJ (2015) Are there modifiable risk factors to prevent a cerebrospinal fluid leak following vestibular schwannoma surgery? J Neurosurg 122:312-316. https://doi.org/10.3171/2014.10.JNS14432

12. Dasenbrock HH, Angriman F, Smith TR, Gormley WB, Frerichs KU, Aziz-Sultan MA, Du R (2017) Readmission After aneurysmal subarachnoid hemorrhage: a nationwide readmission database analysis. Stroke 48:2383-2390. https://doi.org/10.1161/STROK EAHA.117.016702

13. Dasenbrock HH, Smith TR, Rudy RF, Gormley WB, Aziz-Sultan MA, Du R (2018) Reoperation and readmission after clipping of an unruptured intracranial aneurysm: a National Surgical Quality
Improvement Program analysis. J Neurosurg 128:756-767. https:// doi.org/10.3171/2016.10.JNS161810

14. Dasenbrock HH, Yan SC, Chavakula V, Gormley WB, Smith TR, Claus EB, Dunn IF (2017) Unplanned Reoperation after craniotomy for tumor: a national surgical quality improvement program analysis. Neurosurgery 81:761-771. https://doi.org/10.1093/neuros/nyx089

15. Falcioni M, Fois P, Taibah A, Sanna M (2011) Facial nerve function after vestibular schwannoma surgery. J Neurosurg 115:820 826. https://doi.org/10.3171/2011.5.JNS101597

16. Fenton JE, Chin RY, Fagan PA, Sterkers O, Sterkers JM (2002) Predictive factors of long-term facial nerve function after vestibular schwannoma surgery. Otol Neurotol 23:388-392. https://doi. org/10.1097/00129492-200205000-00027

17. Fong B, Barkhoudarian G, Pezeshkian P, Parsa AT, Gopen Q, Yang I (2011) The molecular biology and novel treatments of vestibular schwannomas. J Neurosurg 115:906-914. https://doi. org/10.3171/2011.6.JNS11131

18. Freeman SR, Ramsden RT, Saeed SR, Alzoubi FQ, Simo R, Rutherford SA, King AT (2007) Revision surgery for residual or recurrent vestibular schwannoma. Otol Neurotol 28:1076-1082. https://doi.org/10.1097/MAO.0b013e318159e76a

19. Gardner G, Robertson JH (1988) Hearing preservation in unilateral acoustic neuroma surgery. Ann Otol Rhinol Laryngol 97:55-66. https://doi.org/10.1177/000348948809700110

20. Gerganov VM, Klinge PM, Nouri M, Stieglitz L, Samii M, Samii A (2009) Prognostic clinical and radiological parameters for immediate facial nerve function following vestibular schwannoma surgery. Acta Neurochir (Wien) 151:581-587; discussion 587. https://doi.org/10.1007/s00701-009-0288-3

21. Goddard JC, Meyer T, Nguyen S, Lambert PR (2010) New considerations in the cause of spontaneous cerebrospinal fluid otorrhea. Otol Neurotol 31:940-945. https://doi.org/10.1097/mao.0b013 e3181e8f36c

22. Gupta S, Ahmed AK, Bi WL, Dawood HY, Iorgulescu JB, Corrales CE, Dunn IF, Smith TR (2019) Predicting readmission and reoperation for benign cranial nerve neoplasms: a nationwide analysis. World Neurosurg 121:e223-e229. https://doi.org/10. 1016/j.wneu.2018.09.081

23. Haque R, Wojtasiewicz TJ, Gigante PR, Attiah MA, Huang B, Isaacson SR, Sisti MB (2011) Efficacy of facial nerve-sparing approach in patients with vestibular schwannomas. J Neurosurg 115:917-923. https://doi.org/10.3171/2011.7.JNS101921

24. Hatch JL, Bauschard MJ, Nguyen SA, Lambert PR, Meyer TA, McRackan TR (2018) National trends in vestibular schwannoma surgery: influence of patient characteristics on outcomes. Otolaryngol Head Neck Surg 159:102-109. https://doi.org/10.1177/ 0194599818765717

25. House JW, Brackmann DE (1985) Facial nerve grading system. Otolaryngol Head Neck Surg 93:146-147. https://doi.org/10. 1177/019459988509300202

26. Joynt KE, Jha AK (2013) A path forward on Medicare readmissions. N Engl J Med 368:1175-1177. https://doi.org/10.1056/ NEJMp1300122

27. Kim DH, Morales M, Tai R, Hergenroeder G, Shah C, O’Leary J, Harrison N, Edquilang G, Paisley E, Allen-McBride E, Murphy A, Smith J, Gormley W, Spielman A (2017) Quality programs in neurosurgery: the Memorial Hermann/University of Texas Experience. Neurosurgery 80:S65-S74. https://doi.org/10.1093/neuros/ nyw 158

28. Koos WT, Day JD, Matula C, Levy DI (1998) Neurotopographic considerations in the microsurgical treatment of small acoustic neurinomas. J Neurosurg 88:506-512. https://doi.org/10.3171/jns. 1998.88.3.0506 
29. Kshettry VR, Hsieh JK, Ostrom QT, Kruchko C, Barnholtz-Sloan JS (2015) Incidence of vestibular schwannomas in the United States. J Neurooncol 124:223-228. https://doi.org/10.1007/ s11060-015-1827-9

30. Lohmann S, Brix T, Varghese J, Warneke N, Schwake M, Suero Molina E, Holling M, Stummer W, Schipmann S (2020) Development and validation of prediction scores for nosocomial infections, reoperations, and adverse events in the daily clinical setting of neurosurgical patients with cerebral and spinal tumors. J Neurosurg:1-11. https://doi.org/10.3171/2020.1.JNS193186

31. MacKenzie R, Sporns P, Zoubi T, Koopmann M, Ewelt C, Stummer W, Brokinkel B, Suero Molina E (2018) The difficulty of predicting clinical outcome after intended submaximal resection of large vestibular Schwannomas. J Clin Neurosci 50:62-68. https:// doi.org/10.1016/j.jocn.2018.01.033

32. Matsushima K, Kohno M, Nakajima N (2019) Hearing preservation in vestibular schwannoma surgery via retrosigmoid transmeatal approach. Acta Neurochir (Wien) 161:2265-2269. https://doi.org/10.1007/s00701-019-04034-9

33. McClelland S 3rd, Guo H, Okuyemi KS (2011) Morbidity and mortality following acoustic neuroma excision in the United States: analysis of racial disparities during a decade in the radiosurgery era. Neuro Oncol 13:1252-1259. https://doi.org/10.1093/ neuonc/nor118

34. McCutcheon BA, Ubl DS, Babu M, Maloney P, Murphy M, Kerezoudis P, Bydon M, Habermann EB, Parney I (2016) Predictors of Surgical site infection following craniotomy for intracranial neoplasms: an analysis of prospectively collected data in the American College of Surgeons National Surgical Quality Improvement Program Database. World Neurosurg 88:350-358. https://doi.org/ 10.1016/j.wneu.2015.12.068

35. Moghavem N, Morrison D, Ratliff JK, Hernandez-Boussard T (2015) Cranial neurosurgical 30-day readmissions by clinical indication. J Neurosurg 123:189-197. https://doi.org/10.3171/2014. 12.JNS14447

36. Monfared A, Corrales CE, Theodosopoulos PV, Blevins NH, Oghalai JS, Selesnick SH, Lee H, Gurgel RK, Hansen MR, Nelson RF, Gantz BJ, Kutz JW Jr, Isaacson B, Roland PS, Amdur R, Jackler RK (2016) Facial nerve outcome and tumor control rate as a function of degree of resection in treatment of large acoustic neuromas: preliminary report of the acoustic Neuroma Subtotal Resection Study (ANSRS). Neurosurgery 79:194-203. https://doi. org/10.1227/NEU.0000000000001162

37. Murphy M, Gilder H, McCutcheon BA, Kerezoudis P, Rinaldo L, Shepherd D, Maloney P, Snyder K, Carlson ML, Carter BS, Bydon M, Van Gompel JJ, Link MJ (2016) Increased operative time for benign cranial nerve tumor resection correlates with increased morbidity postoperatively. J Neurol Surg B Skull Base 77:350-357. https://doi.org/10.1055/s-0036-1572508

38. Nakatomi H, Jacob JT, Carlson ML, Tanaka S, Tanaka M, Saito N, Lohse CM, Driscoll CLW, Link MJ (2017) Long-term risk of recurrence and regrowth after gross-total and subtotal resection of sporadic vestibular schwannoma. J Neurosurg:1-7. https://doi. org/10.3171/2016.11.JNS16498

39. Patni AH, Kartush JM (2005) Staged resection of large acoustic neuromas. Otolaryngol Head Neck Surg 132:11-19. https://doi. org/10.1016/j.otohns.2004.09.094

40. Prell J, Strauss C, Plontke SK, Rampp S (2017) Intraoperative monitoring of the facial nerve : Vestibular schwannoma surgery. HNO 65:404-412. https://doi.org/10.1007/s00106-017-0340-1

41. Samii M, Matthies C (1997) Management of 1000 vestibular schwannomas (acoustic neuromas): hearing function in 1000 tumor resections. Neurosurgery 40:248-260; discussion 260-242. https://doi.org/10.1097/00006123-199702000-00005
42. Samii M, Matthies C (1997) Management of 1000 vestibular schwannomas (acoustic neuromas): the facial nerve--preservation and restitution of function. Neurosurgery 40:684-694; discussion 694-685. https://doi.org/10.1097/00006123-199704000-00006

43. Schipmann S, Akalin E, Doods J, Ewelt C, Stummer W, Suero Molina E (2016) When the Infection hits the wound: matched case-control study in a neurosurgical patient collective including systematic literature review and risk factors analysis. World Neurosurg 95:178-189. https://doi.org/10.1016/j.wneu.2016.07. 093

44. Schipmann S, Brix T, Varghese J, Warneke N, Schwake M, Brokinkel B, Ewelt C, Dugas M, Stummer W (2019) Adverse events in brain tumor surgery: incidence, type, and impact on current quality metrics. Acta Neurochir (Wien) 161:287-306. https://doi. org/10.1007/s00701-018-03790-4

45. Schipmann S, Schwake M, Suero Molina E, Roeder N, Steudel WI, Warneke N, Stummer W (2017) Quality Indicators in cranial neurosurgery: which are presently substantiated? A systematic review. World Neurosurg 104:104-112. https://doi.org/10.1016/j. wneu.2017.03.111

46. Schipmann S, Suero Molina E, Windheuser J, Doods J, Schwake M, Wilbers E, Alsofy SZ, Warneke N, Stummer W (2020) The 30-day readmission rate in neurosurgery-a useful indicator for quality assessment? Acta Neurochir (Wien). https://doi.org/10. 1007/s00701-020-04382-x

47. Schipmann S, Varghese J, Brix T, Schwake M, Keurhorst D, Lohmann S, Suero Molina E, Mauer U, Dugas M, Stummer W (2019) Establishing risk-adjusted quality indicators in surgery using administrative data - an example from neurosurgery. Acta Neurochir (Wien)

48. Schmitt WR, Daube JR, Carlson ML, Mandrekar JN, Beatty CW, Neff BA, Driscoll CL, Link MJ (2013) Use of supramaximal stimulation to predict facial nerve outcomes following vestibular schwannoma microsurgery: results from a decade of experience. $\mathrm{J}$ Neurosurg 118:206-212. https://doi.org/10.3171/2012.10.JNS12 915

49. Strickland BA, Ravina K, Rennert RC, Jackanich A, Aaron K, Bakhsheshian J, Russin JJ, Friedman RA, Giannotta SL (2020) Intentional subtotal resection of vestibular schwannoma: a reexamination. J Neurol Surg B Skull Base 81:136-141. https://doi. org/10.1055/s-0039-1679898

50. Suero Molina E, Schildmacher C, Doods J, Freistuhler M, Hellwig SJ, Stummer W, Schipmann S (2020) The rise of quality indicators in neurosurgery: 30-day unplanned reoperation rate evaluated in 3760 patients-a single-center experience. Acta Neurochir (Wien) 162:147-156. https://doi.org/10.1007/s00701-019-04146-2

51. Suero Molina E, van Eck A, Sauerland C, Schipmann S, Horstmann G, Stummer W, Brokinkel B (2019) Local tumor control and clinical symptoms after gamma knife radiosurgery for residual and recurrent vestibular schwannomas. World Neurosurg 122:e1240 e1246. https://doi.org/10.1016/j.wneu.2018.11.022

52. Sughrue ME, Yang I, Aranda D, Rutkowski MJ, Fang S, Cheung SW, Parsa AT (2011) Beyond audiofacial morbidity after vestibular schwannoma surgery. J Neurosurg 114:367-374. https://doi. org/10.3171/2009.10.JNS091203

53. Torres R, Nguyen Y, Vanier A, Smail M, Ferrary E, Sterkers O, Kalamarides M, Bernardeschi D (2017) Multivariate analysis of factors influencing facial nerve outcome following microsurgical resection of vestibular schwannoma. Otolaryngol Head Neck Surg 156:525-533. https://doi.org/10.1177/0194599816677711

54. Troude L, Boucekine M, Montava M, Lavieille JP, Regis JM, Roche PH (2019) Predictive factors of early postoperative and long-term facial nerve function after large vestibular schwannoma surgery. World Neurosurg 127:e599-e608. https://doi.org/ 10.1016/j.wneu.2019.03.218 
55. Tveiten OV, Carlson ML, Link MJ, Lund-Johansen M (2017) Audiovestibular handicap and quality of life in patients with vestibular schwannoma and "excellent" hearing. Neurosurgery 80:386-392. https://doi.org/10.1227/NEU.0000000000001238

56. Wiet RJ, Mamikoglu B, Odom L, Hoistad DL (2001) Long-term results of the first 500 cases of acoustic neuroma surgery. Otolaryngol Head Neck Surg 124:645-651. https://doi.org/10.1177/ 019459980112400609

57. Zanoletti E, Mazzoni A, Frigo AC, Borsetto D, Cazzador D (2020) Hearing preservation outcomes and prognostic factors in acoustic neuroma surgery: predicting cutoffs. Otol Neurotol 41:686-693. https://doi.org/10.1097/MAO.0000000000002602

Publisher's note Springer Nature remains neutral with regard to jurisdictional claims in published maps and institutional affiliations. 